\title{
PREVALENCE, AWARENESS, TREATMENT AND CONTROL OF HYPERTENSION AND MEDICATION ADHERENCE AMONG ELDERLY IN BARANGAY 836, PANDACAN, MANILA, PHILIPPINES
}

\author{
R. Arellano ${ }^{1,2,3^{*}}$, JP. Ramos ${ }^{1,2}$, M. Delacruz ${ }^{1,2}$, R. Lequin ${ }^{1}$, \\ CA. Gregorio ${ }^{1}$ and MD. Dean ${ }^{1,2}$ \\ ${ }^{1}$ Graduate School, \\ ${ }^{2}$ School of Pharmacy, and ${ }^{3}$ Community Outreach Department, \\ Centro Escolar University, 9 Mendiola St., San Miguel, Manila, Philippines.
}

\begin{abstract}
Hypertension is a global public health issue and a major cause of morbidity and mortality. Hypertension is very common among the elderly and with a rapidly aging population, the prevalence of hypertension continues to rise, placing a substantial and escalating social and economic burden. This cross-sectional, population-based study assessed the prevalence and associated risk factors, awareness, treatment and control of hypertension among elderly residents of Barangay 836, Pandacan, Manila, as well as their medication adherence. A total of 108 eligible participants $(72 \%$ response rate) completed an interviewer-administered questionnaire and undergone health examination focusing on BP and BMI measurement. Hypertension prevalence was $81.5 \%$. Of the individuals who have hypertension, $77.3 \%$ were aware of their condition and $72.7 \%$ of the hypertensive participants were receiving antihypertensive drugs. However, only $15.9 \%$ of these participants achieved blood pressure control (130/80) according to the ACC/AHA recommendation. Multivariate logistic regression analysis showed that participants with family history of HTN and age 60 to 79 years are significant risk factors in the development of hypertension in this study $(\mathrm{OR}>1, \mathrm{p}<0.05)$. Medication adherence was evaluated indicating about two-thirds of hypertensive participants have poor knowledge of HTN and its treatment, and majority (82.5\%) exhibited non-perfect adherence in the management of hypertension. Significant findings of this study can be utilized by health care providers and researchers to determine the recent local situation of hypertension and better understand their patients' level of medication adherence for designing effective hypertension prevention and management programs in the country.
\end{abstract}

Keywords: Health assessment, hypertension, Philippines and urban.

\section{INTRODUCTION}

Hypertension (HTN) has been the leading cause of mortality in South-East Asia (SEA), similar to the worldwide statistics. Although this region has been perceived to be less prone to cardiovascular diseases (CVDs), the prevalence of HTN has been reported to be about $35 \%$. In addition, awareness and control of hypertension in SEA is also low, both being below $50 \%{ }^{1}$. The high level of prevalence of hypertension has attributed to the present pandemic of CVDs and death. 
Existing literatures suggest that the proportion of people with hypertension increases with $\mathrm{age}^{2}$. Individuals with normal blood pressure at 55 years of age have a $90 \%$ lifetime risk for developing $\mathrm{HTN}^{3}$. In fact, the elderly constitute an important group in the epidemiology of hypertension. Of all age groups, they have the highest prevalence of hypertension and are at particularly high risk of hypertension-related diseases ${ }^{4}$. Recognizing the elderly as an atrisk population, earlier studies in various countries reported the prevalence, awareness, treatment and control of hypertension among the elderly ${ }^{5-8}$.

The elderly population is increasing in developing countries as they undergo demographic transition, with a concomitant increase in life expectancy. Indeed, it is estimated that by the year 2050 , the majority of the elderly people worldwide will reside in low- and middle-income countries ${ }^{9}$. Most of the cardiovascular health burden attributable to hypertension occurs in the developing world ${ }^{10}$. Therefore, with a rapidly aging population, the prevalence of HTN and related cardiovascular morbidity in Asian patients continues to rise, placing a substantial and escalating social and economic burden on this region.

Hypertension among the elderly is treatable, and blood pressure lowering can reduce the incidence of major coronary events and stroke $^{11,12}$. However, despite the effectiveness of treatment, studies report that elderly with hypertension have the lowest levels of BP control compared with younger age group, even if they are more aware of their hypertension and more likely to be under medication $^{13}$.

Medication adherence has been increasingly recognized as an important factor in elderly persons' health. Various studies have shown that medication non-adherence is associated with poor health status in this population. Understanding factors associated with adherence level is a key component in the management of hypertension among elderly.

Despite these alarming trends, studies on HTN among elderly in urban areas are limited, especially in the Philippines. Although available national data survey (FNRI, 2013) did assess the prevalence of HTN, it did not focus exclusively on elderly. Thus, this present study aimed to;

1. Investigate the prevalence and distribution of hypertension, and associated risk factors,

2. Determine the status of awareness, treatment and control of hypertension among elderly in Barangay 836, Pandacan, Manila, Philippines, and

3. Assess the medication adherence level and its associated factors among elderly hypertensives.

\section{METHODS \\ Study Design and Participants}

A cross-sectional, population-based study was conducted in the Barangay 836, Pandacan, Manila on March, 2018. Target participants were elderly/senior citizens (60 years old and above) and permanent residents of Brgy. 836, Pandacan, Manila. Residents who were hospitalized, with cognitive impairment or unable to communicate verbally were excluded. From the reference population of 241 elderly based on the community registry, a sample size of 150 was predicted. A simple random sampling design was used. Each participant was given explanation about the procedure and objectives of the study. Written and oral consent were obtained from the participants. Confidentiality was assured and they were informed that their participation is fully voluntary and they could freely opt out if they chose. A total of 108 eligible participants $(72 \%$ response rate) completed an interviewer-administered questionnaire and undergone health examination focusing on BP and BMI measurement.

\section{Data Collection}

A modified pre-validated questionnaire $6,8,15$ was used and developed into a multi-item structured questionnaire to elicit the following information; socio-demographic information, $\mathrm{BP}$ and BMI, lifestyle habits, medical history, and item-scale questions assessing key factors related to treatment adherence. From existing literatures, these factors include knowledge of HTN and treatment ${ }^{16}$, patientdoctor relationship ${ }_{15}^{17}$, medication beliefs ${ }^{18}$ and patient adherence ${ }^{15}$.

An examination site was set up in the community hall. During the course of interview, two sitting blood pressure measurements were performed using a mercury sphygmomanometer, according to a common protocol adapted from procedures recommended by the American Heart Association $^{19}$. The inter-rater reliability of the physical examination covering the BP measurement ranges from $0.91-1^{20}$. Body weight was measured using a digital scale. Height was measured (to the nearest $0.5 \mathrm{~cm}$ ) with the participant in an erect position against a vertical surface.

Hypertension is defined as a mean systolic blood pressure (SBP) of $\geq 130 \mathrm{mmHg}$, a mean diastolic blood pressure (DBP) of $\geq 80 \mathrm{mmHg}$, or current use of medication to lower blood pressure $^{19}$. Awareness of hypertension was defined as being perceived by the 
participants who were diagnosed as hypertensive by physicians. Treatment for hypertension was measured by those being aware of their prior diagnosis of hypertension and who were using prescribed antihypertensive drugs. Control of hypertension refers to those who were treated, taking antihypertensive drugs having a mean SBP $<130 \mathrm{mmHg}$ and a mean DBP $<80$ $\mathrm{mmHg}$ among elderly hypertensives.

\section{Knowledge of Hypertension}

This consists of 9 items assessing general knowledge about HTN and drug treatments. Good knowledge of HTN required correct responses to the 4 questions on this topic in the questionnaire. Similarly, the patient's knowledge of anti-hypertensive drugs was also obtained from the specific questions on this topic in the questionnaire.

\section{Beliefs about Medication}

The 18-item questionnaire (BMQ) comprises two sections that evaluate participants' beliefs about the necessity of their medication in disease management and their concerns on its potential adverse effects. Respondents indicate their degree of agreement with each statement on a five-point Likert scale, ranging from 1-strongly disagree to 5-strongly agree. Scores obtained for individual items within both scales are summed. Higher scores indicate stronger beliefs.

\section{Patient-Doctor Relationship}

The 9-item based questionnaire (PDRQ-9) measures the doctor-patient relationship from the patient's perspective, which has been assessed specifically in primary care. Also, respondents indicate their degree of agreement with each statement on a five-point Likert scale, ranging from 1-strongly disagree to 5-strongly agree.

Patient Adherence. The Hill-Bone Medication Adherence (HBMA) Scale consists of 9 fourpoint Likert-type items (1-none of time, 2-some of the time, 3-most of time, and 4-all the time) that measures patient's self-reported compliance.

\section{Statistical Analysis}

Descriptive statistics were used to report the prevalence, awareness, treatment, and control of HTN. The associations between categorical (e.g. socio-demographic, health-related and lifestyle-related) variables were tested by the use of contingency tables and the Chi-square test. Multivariate logistic regression analysis was conducted to investigate the factors associated with the prevalence of hypertension. Odds ratios (ORs) with 95\% confidence intervals $(95 \% \quad$ Cls $)$ for hypertension status were also calculated. All statistical analyses were performed using XLSTAT 2018.2.50198. p value of less than 0.05 is considered statistically significant.

\section{RESULTS}

The prevalence of hypertension was $81.5 \%$ $(88 / 108)$ among study participants. Table 1 shows the distribution of socio-demographic and life-style related factors by hypertension prevalence rates, awareness, treatment and control. In this study group, gender, educational attainment and family history of HTN are significantly associated with the prevalence of hypertension (Chi-square, $\mathrm{p}<0.05)$.

Of the individuals who have hypertension, $77.3 \%$ (68/88) were aware of their condition. Similarly with prevalence, females and those having a family history of HTN, as well as current or past smokers were more aware of their hypertension. $72.7 \% \quad(64 / 88)$ of the hypertensive participants were receiving antihypertensive drugs. However, only $15.9 \%$ $(14 / 88)$ of these participants achieved blood pressure control (130/80) according to the ACC/AHA recommendation. No statistical differences were observed in awareness, treatment and control by age, marital status, employment status, BMI, eating habit and alcohol consumption (Chi-square, $p<0.05$ ).

In order to further analyze risk factors of hypertension, hypertension was taken as dependent variable, while age, gender, marital status, educational attainment, employment status, BMI, family history of HTN, eating habit, smoking and alcohol consumption as independent variables. Multivariate logistic regression analyses were performed to find independent association of these factors. Table 2 presents predictors of HTN which confirms the importance of a number of factors identified in Table 1. Particularly, individuals in lower age group level appeared to have higher risk of developing hypertension (OR $>1$, $p<0.05)$. Compared with participants with nonformal education, those who finished primary or secondary level were more likely to suffer from hypertension $(O R>1, p<0.05)$. In addition, hypertensive individuals with a family history of HTN had a higher chance of developing hypertension than those without (OR>1, $p<0.05)$. Gender, marital status, employment status, BMI and lifestyle-related habits were not independently associated with hypertension based on the results of the analysis.

Eighty out of the eighty-eight hypertensive participants completed the questionnaires that assess adherence level with a response rate 
of $90.9 \%$. Table 3 summarizes the adherence level and its associated factors to hypertension management. Two out of three participants had poor knowledge with regards to hypertension and its treatment. Majority of the sample $(82.5 \%)$ believed in the necessity of their medication for maintaining health (i.e. had scores greater than the scale midpoint). $60 \%$ of the study sample (had score higher than scale midpoint) were concerned about potential long-term effects and dependence on the drug, too much trust on their physician, and safety of natural remedies over anti-HTN drugs. Likewise, for the level of satisfaction, $90 \%$ of the participants had good relationship with their doctors. Unfortunately, patient adherence, as evaluated by HBMA scale, resulted to a relatively low (17.5\%) perfect adherence among study sample.

\section{DISCUSSION}

The present study showed that the prevalence of hypertension in the study group (81.5\%) was higher compared to the $8^{\text {th }}$ National Nutrition Survey conducted by the Food and Nutrition Research Institute of the Department of Science and Technology, Philippines in 2013 reporting prevalence rates of $33.1 \%$ among $60-69$ years old and $34.1 \%$ among 70 years old and above ${ }^{21}$. It was also higher than those in Asian countries such as Taiwan $(60.4 \%)^{5}$, Korea $(68.7 \%)^{6}$, Thailand $(51.1 \%)^{7}$, China $(48.5 \%)^{8}$ and Singapore $(73.9 \%)^{22}$.

Similar to previous studies, the association of hypertension with gender, family history of HTN and educational background was observed $^{6,8,23}$. However, from the multivariate analysis, although elderly female Filipinos had a higher prevalence of hypertension than men, the relationship was considered not statistically significant. In contrast to findings from developed countries, where risk factors for cardiovascular diseases, including hypertension, are more pronounced among the less educated groups, higher educational levels is associated with increased chances of hypertension ${ }^{24}$. Still, a family history of HTN was determined to be strong predictor of hypertension in this study, supporting similar findings in different populations ${ }^{8,23}$.

Overall, the rates of awareness and treatment of hypertension among study subject is higher than most studies from other countries, although a few studies reported similar figures $^{5-8,22}$. The levels of awareness and treatment of hypertension are contingent efforts aimed at raising awareness about hypertension, together with the efficiency of health-care services in detecting hypertension and initiating treatment. Thus, these findings suggest good public health awareness, screening programs and health-care services in the country. In the Philippines, the Department of Health (DOH) is continuously addressing hypertension through many strategies and initiatives such as screening for hypertension and other non-communicable diseases like diabetes in health facilities nationwide. People who are diagnosed with hypertension are enrolled in the $\mathrm{DOH}$ Hypertension and Diabetes Registry and Club for regular follow-up medical examination with provision of maintenance medicines ${ }^{25}$.

Although not statistically significant, a low control percentage was observed among hypertensive participants undergoing treatment. Such finding might be attributed from lack of information on the right management of hypertension. Some patients did not know that they needed to take antihypertensive drugs in their whole lives. Instead, they believed that they could stop taking the drugs when their BP was checked and found "normal". Therefore, it is crucial to promote health education to enable the communities to realize the importance of treatment adherence and regular medical check-ups. Antihypertension programs in communities can be implemented for regular monitoring of blood pressure as well as pharmacological treatment regimen of people with hypertension.

Further, from the perspective that a family history of HTN and age 60 to 79 years are strongly associated with hypertension in this study, immediate relatives of persons diagnosed with hypertension should be monitored and advised to have their blood pressure regularly checked. Older residents should also be similarly advised.

Medication adherence is a key component in the management for patients with hypertension. The key to design interventions to improve medication adherence is a greater understanding of the factors related to poor. Patient-Doctor Relationship gives the opportunity to assess the communication, level of satisfaction and availability in dealing with the physician in regard to patient's point of view $^{26}$. With higher percentage showing good relationship, this indicated better level of satisfaction among participants. Majority have positive beliefs about the necessity of their medication. However, strong concerns about potential adverse effects and drug dependence were expressed by more than half of the participants.

Major findings indicate that about two-thirds of hypertensive participants have poor knowledge of HTN and its treatment, and majority exhibited non-perfect adherence in hypertension management. Thus, intervention 
must be directed towards improving knowledge and adherence in individuals by regularly attending an educational program during outpatient visits scheduled by primary care health-providers to achieve better control of hypertension.

\section{CONCLUSION}

The study revealed that the prevalence of hypertension among elderly Filipinos is higher than most Asian countries. From several contributing factors to such difference, gender, educational attainment and family history of HTN were significantly associated with the prevalence of hypertension. However, elderly in the lower age groups and with family history of HTN had higher risks of developing the disease. Despite acceptable level of treatment and awareness, the alarmingly low rate of control among elderly hypertensives is an indicative of the need for immediate strategies and interventions to improve BP control. Medication adherence is an important factor that must be addressed for successful treatment and control of HTN in this high-risk population.

Health care providers and researchers can utilize the findings of this study to ascertain the up-to-date local situation of hypertension and better understand their patients' level of medication adherence for designing effective hypertension prevention and management programs.

Table 1: Percent (\%) Distribution of Socio-Demographic and Lifestyle-related Factors and Hypertension Status among Elderly in Barangay 836, Pandacan, Manila (March 2018)

\begin{tabular}{|c|c|c|c|c|c|}
\hline & $\begin{array}{c}\text { Total } \\
(n=108)\end{array}$ & $\begin{array}{c}\text { HTN } \\
\text { Prevalence } \\
(n=108)^{a}\end{array}$ & $\begin{array}{c}\text { HTN } \\
\text { Awareness } \\
(n=88)^{b}\end{array}$ & $\begin{array}{c}\text { HTN } \\
\text { Treatmen } \\
t \\
(\mathrm{n}=88)^{\mathrm{b}}\end{array}$ & $\begin{array}{c}\text { HTN } \\
\text { Control } \\
(n=88)^{b}\end{array}$ \\
\hline \multicolumn{6}{|l|}{ Age } \\
\hline $60-70$ & 46.3 & 40.7 & 36.4 & 34.1 & 11.4 \\
\hline $71-80$ & 38.9 & 31.5 & 29.5 & 27.3 & 4.5 \\
\hline 81 and above & 14.8 & 9.3 & 11.4 & 11.4 & 0.0 \\
\hline \multicolumn{6}{|l|}{ Gender } \\
\hline Male & 18.5 & 18.5 & 22.7 & 20.5 & 4.5 \\
\hline Female & 81.5 & $63.0^{*}$ & $54.5^{*}$ & 52.3 & 11.4 \\
\hline \multicolumn{6}{|l|}{ Marital Status } \\
\hline Single & 3.7 & 3.7 & 2.3 & 2.3 & 0.0 \\
\hline Married/Cohabiting & 40.7 & 32.4 & 36.4 & 31.8 & 6.8 \\
\hline Widowed/Divorced/Separated & 53.7 & 36.1 & 38.6 & 38.6 & 9.1 \\
\hline \multicolumn{6}{|l|}{ Educational Attainment } \\
\hline Non- formal Education & 7.4 & 3.7 & 2.3 & 2.3 & 0.0 \\
\hline Primary & 37.0 & 35.2 & 37.5 & 34.1 & 4.5 \\
\hline Secondary & 50.0 & $42.6^{*}$ & 37.5 & 36.4 & 11.4 \\
\hline Tertiary & 5.6 & 0.0 & 0.0 & 0.0 & 0.0 \\
\hline \multicolumn{6}{|l|}{ Employment Status } \\
\hline Unemployed & 81.5 & 66.7 & 59.1 & 54.5 & 9.1 \\
\hline Employed (Health-related) & 1.9 & 1.9 & 2.3 & 2.3 & 0.0 \\
\hline Employed (Not health-related) & 16.7 & 13.0 & 15.9 & 15.9 & 6.8 \\
\hline \multicolumn{6}{|l|}{ BMI } \\
\hline Underweight: $\mathrm{BMl}<18.50$ & 9.3 & 5.6 & 3.4 & 3.4 & 2.3 \\
\hline Normal: BMI (18.5-22.99) & 33.3 & 25.9 & 26.1 & 23.9 & 4.5 \\
\hline Overweight: BMI (23-24.99) & 24.1 & 20.4 & 15.9 & 15.9 & 4.5 \\
\hline Obese: $\mathrm{BMI}>25$ & 33.3 & 29.6 & 31.8 & 29.5 & 4.5 \\
\hline \multicolumn{6}{|l|}{ Family History of HTN } \\
\hline Yes & 42.6 & $40.7^{*}$ & $34.1^{*}$ & 33.0 & 2.3 \\
\hline No & 57.4 & 40.7 & 43.2 & 39.8 & 13.6 \\
\hline \multicolumn{6}{|l|}{$\begin{array}{l}\text { Eating Habit (salted/preserved } \\
\text { food) }\end{array}$} \\
\hline Less than once per month & 38.9 & 28.7 & 27.3 & 25.0 & 9.1 \\
\hline Twice or thrice a month & 38.9 & 32.4 & 28.4 & 26.1 & 2.3 \\
\hline Two or three times a week & 18.5 & 16.7 & 17.0 & 17.0 & 4.5 \\
\hline More than four times a week & 3.7 & 3.7 & 4.5 & 4.5 & 0.0 \\
\hline \multicolumn{6}{|l|}{ Smoking } \\
\hline Non-smoker & 83.3 & 68.5 & 61.4 & 59.1 & 9.1 \\
\hline Current or past smoker & 16.7 & 13.0 & $15.9^{*}$ & 13.6 & 6.8 \\
\hline \multicolumn{6}{|l|}{ Alcohol consumption } \\
\hline Non-drinker & 81.5 & 64.8 & 62.5 & 60.2 & 6.8 \\
\hline Occasional & 18.5 & 16.7 & 14.8 & 12.5 & 9.1 \\
\hline \multicolumn{6}{|l|}{ Exercise } \\
\hline $\begin{array}{c}\text { Lack of exercise } \\
\text { (less than once a month) }\end{array}$ & 22.2 & 21.3 & 20.5 & 20.5 & 2.3 \\
\hline $\begin{array}{l}\text { Occasional exercise (once a month } \\
\text { or less than } 3 x \text { per week) }\end{array}$ & 31.5 & 23.1 & 26.1 & 25.0 & 9.1 \\
\hline Regular exercise ( $\geq 3$ per week) & 46.3 & 37.0 & 30.7 & 27.3 & 4.5 \\
\hline
\end{tabular}


Table 2: Multivariate Analysis of Risk Factors of Hypertension

\begin{tabular}{|c|c|c|}
\hline Variable & $\begin{array}{c}\text { Odds Ratio } \\
\text { (95\% Confidence } \\
\text { Level) }\end{array}$ & $\begin{array}{c}\text { p- } \\
\text { value }\end{array}$ \\
\hline \multicolumn{3}{|l|}{ Age } \\
\hline $60-70$ & $4.400(1.171-16.531)$ & 0.028 \\
\hline $71-80$ & $2.550(0.715-16.531)$ & 0.149 \\
\hline 81 and above & Reference & \\
\hline \multicolumn{3}{|l|}{ Gender } \\
\hline Male & Reference & \\
\hline Female & --- & 0.992 \\
\hline \multicolumn{3}{|l|}{ Marital Status } \\
\hline Single & Reference & \\
\hline Married/Cohabiting & --- & 0.993 \\
\hline Widowed/Divorced/Separated & --- & 0.993 \\
\hline \multicolumn{3}{|l|}{ Educational Attainment } \\
\hline Non- formal Education & Reference & \\
\hline Primary & $\begin{array}{c}19.000(2.609- \\
138.383)\end{array}$ & 0.004 \\
\hline Secondary & $5.750(1.189-27.810)$ & 0.030 \\
\hline Tertiary & ---- & 0.991 \\
\hline \multicolumn{3}{|l|}{ Employment Status } \\
\hline Unemployed & Reference & \\
\hline Employed (Health-related) & --- & 0.994 \\
\hline Employed (Not health-related) & $0.778(0.226-2.678)$ & 0.690 \\
\hline \multicolumn{3}{|l|}{ BMI } \\
\hline Underweight: $\mathrm{BMl}<18.50$ & $0.321(0.069-1.502)$ & 0.149 \\
\hline Normal: BMI (18.5-22.99) & Reference & \\
\hline Overweight: BMI (23-24.99) & $1.179(0.296-4.698)$ & 0.816 \\
\hline Obese: $\mathrm{BMI}>25$ & $1.143(0.331-3.949)$ & 0.833 \\
\hline \multicolumn{3}{|l|}{ Family History of HTN } \\
\hline Yes & $9.000(1.969-41.128)$ & 0.005 \\
\hline No & Reference & \\
\hline \multicolumn{3}{|l|}{ Eating Habit (salted/preserved food) } \\
\hline Less than once per month & Reference & \\
\hline Twice or thrice a month & $3.194(0.635-16.052)$ & 0.159 \\
\hline Two or three times a week & $1.774(0.612-5.140)$ & 0.291 \\
\hline More than four times a week & --- & 0.991 \\
\hline \multicolumn{3}{|l|}{ Smoking } \\
\hline Non-smoker & Reference & \\
\hline Current or past smoker & $1.321(0.384-4.546)$ & 0.658 \\
\hline \multicolumn{3}{|l|}{ Alcohol consumption } \\
\hline Non-drinker & Reference & \\
\hline Occasional & $2.314(0.491-10.903)$ & 0.289 \\
\hline \multicolumn{3}{|l|}{ Exercise } \\
\hline $\begin{array}{c}\text { Lack of exercise (less than once a } \\
\text { month) }\end{array}$ & $5.750(0.691-47.839)$ & 0.106 \\
\hline $\begin{array}{c}\text { Occasional exercise (once a month or } \\
\text { less than } 3 x \text { per week) }\end{array}$ & $0.694(0.248-1.945)$ & 0.488 \\
\hline Regular exercise ( $\geq 3$ per week) & Reference & \\
\hline
\end{tabular}

Table 3: Assessment of Adherence Level and Associated Factors among Hypertensive Participants $(n=80)$

\begin{tabular}{|c|c|c|}
\hline Factors & Frequency & $\%$ \\
\hline $\begin{array}{c}\text { Knowledge of Hypertension and } \\
\text { Antihypertensive Drugs }\end{array}$ & & \\
\hline Low Knowledge & 52 & 65.0 \\
\hline High Knowledge & 28 & 35.0 \\
\hline Belief About Medication (Necessity) & 14 & \\
\hline Low Necessity & 66 & 17.5 \\
\hline High Necessity & & \\
\hline Belief About Medication (Concern) & 32 & 40.0 \\
\hline Low Concern & 48 & 60.0 \\
\hline High Concern & & \\
\hline Patient-Doctor Relationship & 8 & 10.0 \\
\hline Poor Relationship & 72 & 90.0 \\
\hline Good Relationship & 66 & \\
\hline Patient Adherence & 14 & 17.5 \\
\hline Non-Perfect Adherence & &
\end{tabular}




\section{REFERENCES}

1. World Health Organization, Regional Office for South East Asia. Report of expert meeting on population sodium reduction strategies for prevention and control of non-communicable diseases in the South East Asia Region: 11-13 December 2012, New Delhi, India. New Delhi: WHO SEARO. 2012.

2. Peng S, Shen T, Liu J, Tomlinson B, Sun $H$, Chen $X$, Chan $P$, Kuang $Y$, Zheng L, Wu H, Ding X, Qian D, Shen Y, Gao P, Fan H, Liu Z and Zhang Y. Uncontrolled Hypertension Increases with Age in an Older CommunityDwelling Chinese Population in Shanghai. Aging and disease. 2017;8(5):558-569.

3. Vasan RS, Beiser A and Seshadri S. Residual lifetime risk for developing hypertension in middle-aged women and men. JAMA. 2002;287:1003-10.

4. Chobanian AV, Bakris GL, Black HR, Cushman WC, Green LA, Izzo JL, Jones DW, Materson BJ, Oparil S and Wright JT. The Seventh Report of the Joint National Committee on Prevention, Detection, Evaluation, and Treatment of High Blood Pressure: the JNC 7 report. JAMA. 2003;289:25602572.

5. Lu FH, Tang SJ, Wu JS, Yang YC, Chang CJ. Hypertension in elderly persons: its prevalence and associated cardiovascular risk factors in Tainan City, southern Taiwan. J Gerontol A Biol Sci Med Sci. 2000;55:M463-M468.

6. Kim KI, Chang HJ, Cho YS, Youn TJ, Chung WY, Chae IH, Choi DJ and Kim $\mathrm{CH}$. Current status and characteristics of hypertension control in community resident elderly Korean people: data from a Korean longitudinal study on health and aging (KLoSHa study). Hypertens Res. 2008;31:97-105.

7. Porapakkham Y, Pattaraarchachai J and Aekplakorn W. Prevalence, awareness, treatment and control of hypertension and diabetes mellitus among the elderly: the 2004 National Health Examination Survey III, Thailand. Singapore Med J. 2008;49:868-873.

8. Zhang $\mathrm{X}$, Zhu M, Dib HH, Hu J, Tang $\mathrm{S}$, Zhong $\mathrm{T}$ and Ming $\mathrm{X}$. Knowledge, awareness, behavior (KAB) and control of hypertension among urban elderly in Western China. Int J Cardiol. 2009;137:9-15.
9. World Health Organization. World report on ageing and health. World Health Organization. 2015. http://www.who.int/iris/handle/10665/1 86463.

10. Lawes CM, Vander Hoorn S and Law MR. Blood pressure and the global burden of disease 2000. Part II: estimates of attributable burden. J Hypertens. 2006;24:423-30.

11. Beckett NS, Peters R, Fletcher AE, Staessen JA, Liu L, Dumitrascu D, Stoyanovsky V, Borah B, Sacco P and Zarotsky V. Predictors of adherence among Alzheimer's disease patients receiving oral therapy. Curr Med Res Opin. 2010;26:1957-65.

12. Rigaud AS and Forette B. Hypertension in older adults. $\mathrm{J}$ Gerontol A Biol Sci Med Sci. 2001;56:M217-M225.

13. Pinto E. Blood pressure and ageing. Postgraduate medical journal. 2007;83(976):109-14.

14. Ownby RL. Medication adherence and cognition. Medical, personal and economic factors influence level of adherence in older adults. Geriatrics. 2006;61:30-5

15. Alsolami F, Xiang-Yu H, and CorreaVelez I. An Arabic instrument to measure medication adherence in Saudi hypertensive patients. Middle Eastern Journal of Family Medicine. 2013; 7(11):17-23.

16. Karaeren $H$, Yokuşoğlu $M$, Uzun Ş, Baysan O, Köz C, Kara B and Uzun $M$. The effect of the content of the knowledge on adherence to medication in hypertensive patients. Anadolu Kardiyoloji Dergisi. 2009;9(3):183-188.

17. Chin JJ. Doctor-patient relationship: a covenant of trust. Singapore Medical Journal. 2001;42(12):579.

18. Horne $\mathrm{R}$, Weinman $\mathrm{J}$ and Hankins $\mathrm{M}$. The beliefs about medicines questionnaire: The development and evaluation of a new method for assessing the cognitive representation of medication. Psychology and Health. 1999;14(1):1-24.

19. ACC/AHA/AAPA/ABC/ACPM/AGS/AP hA/ASH/ASPC/NMA/PCNA Guideline for the Prevention, Detection, Evaluation, and Management of High Blood Pressure in Adults: A Report of the American College of Cardiology/American Heart Association Task Force on Clinical 
Practice Guidelines. J Am Coll Cardiol. 2017.

20. Sit WH, Li SJ, Zheng YL, Wong MYE and $\mathrm{Wu} \mathrm{ZP}$. Prevalence and Risk Factors Associated With Prehypertension: Identification of Foci for Primary Prevention of Hypertension. J Cardiovas Nur. 2010;25:461-469.

21. Food and Nutrition Research InstituteDepartment of Science and. Technology. Philippine Nutrition Facts and Figures 2013: 8th National Nutrition Survey. 2013.

22. Malhotra R, Chan A, Malhotra $C$ and Østbye T. Prevalence, awareness, treatment and control of hypertension in the elderly population of Singapore. Hypertens Res. 2010;33:1223-31.

23. Joshi V, Lim J and Nandkumar M. Prevalence and risk factors of undetected elevated blood pressure in an elderly Southeast Asian population. Asia Pac J Public Health. 2007;19:39.

24. Pereira $M$, Lunet $N$, Azevedo $A$ and Barros $\mathrm{H}$. Differences in prevalence, awareness, treatment and control of hypertension between developing and developed countries. J Hypertens. 2009;27:963-975.

25. Department of Health, Department of Health Progress on the first year of three-year Statement of Strategy 2015 - 2017 Annual Report 2015. Dublin: $\mathrm{DOH}$

26. Arafat SMY. Psychometric validation of the Bangla version of the patientdoctor relationship questionnaire. Psychiatry Journal. 2016;2016:4. 